\title{
"Much ado about nothing": monoamine oxidase inhibitors, drug interactions, and dietary tyramine
}

\author{
Ken Gillman*
}

PsychoTropical Research, Bucasia, Queensland, Australia

First published online 2 February 2017

"Sigh no more, Ladies, sigh no more, Men were deceivers ever, One foot in sea and one on shore, To one thing constant never." -Shakespeare, Much Ado About Nothing

\section{Introduction}

The era of those physicians whose early practice was informed by familiarity with the (even now) unsurpassed efficacy, for severe depression, of monoamine oxidase inhibitors (MAOI), is ending. A number of authors have reviewed this subject and noted the continuing decline in the use of MAOIs, and also the fact that younger physicians have almost no experience of them. ${ }^{1-4}$ It has also been observed that they continue to be recommended in most guidelines, and that they are invaluable in the treatment of severe and intractable cases of depression. ${ }^{4-14}$ It is noteworthy, contrary to popular current belief, that patients themselves frequently rate MAOIs as being more effective than "newer" drugs and as having fewer side effects. ${ }^{15-17}$ Many experienced colleagues have shared the satisfaction of seeing patients who have enjoyed complete remission from many years of illness, after only a few weeks on an MAOI, having previously failed to get an adequate response from the panoply of modern remedies (as well as ECT). Such patients, understandably, may be angry that they were not even offered the option of such treatment earlier in the burdensome course of their suffering. Even when patients have requested an MAOI, it has often been refused, with a comment such as "we don't use drugs like that any more, they're dangerous."

So, after more than 50 years, where are we? What explains this discrepancy between the published literature and the view of experienced practitioners contrasted with

\footnotetext{
* Address for correspondence: Ken Gillman, PsychoTropical Research, PO Box 86, Rural View, Queensland, 4740 Australia.

(Email: kg@matilda.net.au)
}

the reality of the near-total lack of use of MAOIs? (Current usage is about $0.1 \%$ of all antidepressant scripts. ${ }^{7}$ )

The purpose of this editorial is to address this discrepancy, to draw attention to recent data, to encourage doctors to consider these drugs earlier in the illness-course of patients, and most particularly to illuminate issues that are perceived as major hurdles. These hurdles cause doctors to shy away from using MAOIs, but they are largely illusory. The two most prominent seem to be (1) the misperception that there are frequent drug interactions and (2) that there is a major risk of ingesting excessive tyramine (Tyr). Neither hurdle is complex nor difficult to overcome if the latest scientific evidence is considered..$^{2,8,18-21}$ The ability to properly manage MAOI treatment should be in the repertoire of all psychiatrists. It is regrettable that this is not the case. Statements that MAOIs are "outmoded" and "dangerous drugs" are both wrong and unprofessional, yet they are frequently encountered.

\section{Drug Interactions}

There are no significant pharmaco-kinetic interactions that involve MAOIs, ${ }^{8}$ which is more than can be said for most other "new" drugs.

The main serious interaction between MAOIs and other therapeutic drugs is the pharmaco-dynamic interaction of serotonin toxicity (ST), which is caused only by the co-ingestion of serotonin reuptake inhibitors (SRIs). Contrary to the opinions expressed in many texts, other so-called "serotonergic" drugs that are not significant SRIs, like trazodone, mirtazapine, tryptans, etc, are not a risk for serious ST interactions. ${ }^{20,22,23}$ For example, mirtazapine is not an SRI, but it is a potent antagonist at post-synaptic 5-HT2A receptors and prevents ST in the animal model. ${ }^{24,25}$ Imipramine is a quintessential example of how the spectrum concept of ST elucidates the clinical potency of drugs. I have elaborated that point previously; see table 3 in Gillman. ${ }^{20}$ Imipramine has 
been involved in many ST interactions, some fatal even in therapuetic doses (eg, most recently, as described in Otte et $a l^{26}$; many cases were documented in the $1960 \mathrm{~s}$ and are described in Gillman ${ }^{27}$ ). Imipramine is "borderline" in relation to precipitating ST at therapeutic doses, and that is consistent with its lower SERT potency (vs clomipramine); that is discussed in detail in Gillman. ${ }^{28}$

Learning which drugs are significant SRIs is straightforward, and the considerations clarifying this are explained in a series of recent review papers. ${ }^{8,18,20,21}$ The sources cited herein have been chosen because they explain and dispel the numerous myths and mistaken assumptions about the use of MAOIs, such as the following:

- They cannot be combined safely with tricyclic antidepressants (false, with the exception of clomipramine and imipramine).

- Serotonin toxicity is possible with a wide range of drugs (false, only potent SRIs).

- It is difficult to swap to and from other drugs (false, in fact one can safely co-administer them with any therapeutic psychotropic drug except one that has significant potency as an SRI).

- They need to be ceased before anesthesia (false), and that opioid analgesia cannot be used (false, except for opiates that are SRIs, such as tramadol and meperidine [pethidine]).

- One cannot give epinephrine, or alpha1 agonists (false, but a small dose reduction may be appropriate).

- They cause elevated BP and should not be used in patients suffering from hypertension (false, they lower $\mathrm{BP}$ and ameliorate hypertension), etc.

\section{Modern diets have greatly reduced levels of tyramine}

Most current diet guides about Tyr in foods contain much misinformation, as do standard texts. ${ }^{13,29}$ An important explanation for this is that data concerning Tyr are largely published in food science journals, most of which are not included in medical literature databases. As a result, medical writers have remained unaware of these data. They are however reviewed and referenced in a detailed monograph, which contains hundreds of Tyr estimations from all types of cheeses (and other foods and drinks, etc), and also explains drug interactions and hypertensive urgencies. ${ }^{30}$

Great changes in food production techniques have occurred in the last decade or two. The main change has been the near-universal adoption of non-decarboxylating starter cultures, which do not produce any Tyr. Those are now used by almost all producers of cheeses, salamis, soy sauces, etc, and in consequence, modern diets have greatly reduced levels of Tyr.

The extremely high concentrations of Tyr encountered in matured or fermented foods in past decades now rarely, if ever, occur. The reported cases that resulted in morbidity in the $1960 \mathrm{~s}$ were estimated with a Tyr concentration of $1,000-3,700 \mathrm{mg} / \mathrm{kg},{ }^{31,32}$ which is 2 orders of magnitude higher than typical concentrations seen now. Nowadays, many matured cheeses have negligible concentrations (ie, $<10 \mathrm{mg} / \mathrm{kg}$ ) of $\mathrm{Tyr},{ }^{30}$ and most of those with higher concentrations (typically no more than $250 \mathrm{mg} / \mathrm{kg}$ ) would need portion sizes of more than $50 \mathrm{~g}$ before becoming at all likely to provoke a risky degree of hypertension (ie, containing $>10 \mathrm{mg}$ of Tyr). Lesser degrees of blood pressure (BP) elevation are nowadays to be expected precisely because the pressor response is a dose-related phenomenon. Therefore, since previously implicated foods now have much lower Tyr concentrations, it is unlikely that injurious quantities will be ingested. Indeed, it is probably the case that unnecessary treatments of BP elevation have caused morbidity when no significant harm from hypertension would otherwise have ensued. That is because administration of major anti-hypertensive drugs risks producing excessive hypotension and consequent cerebral hypo-perfusion. Indeed, experts in the treatment of hypertension state that it is unwise (some say absolutely contra-indicated) to give patients major anti-hypertensive drugs to take themselves when they think they have hypertension. That admonition can be extended to less experienced ER staff. Tyr-induced episodes settle spontaneously within 1-4 hours. The safest and most appropriate intervention now advised is a sedative dose of a benzodiazepine. $^{33-35}$

Tyr's mechanism of action is as an indirectly acting sympathomimetic: that is to say it must be taken up into the presynaptic neuron (by the reuptake pump for epinephrine, the NET), where it then precipitates the mass release of norepinephrine, thus potentially giving rise to an increase in $\mathrm{BP}$, ie, a "pressor" response (NB TCAs block the NET, thereby reducing Tyr's effect on BP). The term "indirectly acting sympathomimetic" has been superseded by the term "releaser." The magnitude of the effect of releasers is much greater than the effect of directly acting agonists, such as epinephrine itself: this was established at the dawn of modern pharmacology by researchers whose names are writ large in history, Gaddum and Brodie, among others, ${ }^{36,37}$ yet that work has been forgotten. We still see statements that one cannot give epinephrine with MAOIs; that was disproved nearly 70 years ago, and that disproof has been replicated ad nauseam. To quote Cicero: "I requiem meam doleat" (I rest my case). Therefore, it is important to understand that releasers such as Tyr can give rise to a marked pressor response, but directly acting agonists, such as epinephrine itself, or directly acting postsynaptic receptor alpha1 agonists, such as midodrine, have minimal BP potentiating interaction when combined with MAOIs. 


\section{Conclusion}

MAOIs have good efficacy in serious depressive illnesses, and, for a competent physician, they are not difficult to use and manage. When the mist of myth is dispersed, it is evident that the subject is straightforward. Doctors wishing to follow the advice of the many authors who espouse more extensive use of these drugs will be well placed to do so confidently and safely when they have acquainted themselves with the updated information in the references and monograph. ${ }^{30}$

\section{Disclosures}

Ken Gillman does not have anything to disclose.

\section{REFERENCES:}

1. Paykel ES, White JL. A European study of views on the use of monoamine oxidase inhibitors. Br J Psychiatry. 1989; 155(Suppl 6): 9-17.

2. Balon R, Mufti R, Arfken CL. A survey of prescribing practices for monoamine oxidase inhibitors. Psychiatr Serv. 1999; 50(7): 945-947.

3. Clary C, Mandos LA, Schweizer E. Results of a brief survey on the prescribing practices for monoamine oxidase inhibitor antidepressants. J Clin Psychiatry. 1990; 51(6): 226-231.

4. Shulman KI, Fischer HD, Herrmann N, Huo CY, Anderson GM, Rochon PA. Current prescription patterns and safety profile of irreversible monoamine oxidase inhibitors: a population-based cohort study of older adults. J Clin Psychiatry. 2009; 70(12): 1681-1686.

5. Heijnen WT, De Fruyt J, Wierdsma AI, Sienaert P, Birkenhager TK. Efficacy of tranylcypromine in bipolar depression: a systematic review. J Clin Psychopharmacol. 2015; 35(6): 700-705.

6. Grady MM, Stahl SM. Practical guide for prescribing MAOIs: debunking myths and removing barriers. CNS Spectr. 2012; 17(1): $2-10$.

7. O'Brien V. The monoamine oxidase inhibitors: relics reconsidered. Psychiatric Annals. 2011; 41(3): 176-183.

8. Gillman PK. Advances pertaining to the pharmacology and interactions of irreversible nonselective monoamine oxidase inhibitors. J Clin Psychopharmacol. 2011; 31(1): 66-74.

9. Mallinger AG, Frank E, Thase ME, et al. Revisiting the effectiveness of standard antidepressants in bipolar disorder: are monoamine oxidase inhibitors superior? Psychopharmacol Bull. 2009; 42(2): 64-74.

10. Fawcett J. Why aren't MAOIs used more often? J Clin Psychiatry. 2009; 70(1): 139-140.

11. Amsterdam JD, Shults J. MAOI efficacy and safety in advanced stage treatment-resistant depression-a retrospective study. J Affect Disord. 2005; 89(1-3): 183-188.

12. Kennedy N, Paykel ES. Treatment and response in refractory depression: results from a specialist affective disorders service. J Affect Disord. 2004; 81(1): 49-53.

13. Fiedorowicz JG, Swartz KL. The role of monoamine oxidase inhibitors in current psychiatric practice. J Psychiatr Pract. 2004; 10(4): 239-248.

14. Nutt D, Glue P. Monoamine oxidase inhibitors: rehabilitation from recent research? Br J Psychiatry. 1989; 154(3): 287-291.

15. Adli M, Pilhatsch M, Bauer M, et al. Safety of high-intensity treatment with the irreversible monoamine oxidase inhibitor tranylcypromine in patients with treatment-resistant depression. Pharmacopsychiatry. 2008; 41(6): 252-257.

16. Parker G, Roy K, Wilhelm K, Mitchell P. Assessing the comparative effectiveness of antidepressant therapies: a prospective clinical practice study. J Clin Psychiatry. 2001; 62(2): 117-125.

17. Parker G, Mitchell P, Wilhelm K, et al. Are the newer antidepressant drugs as effective as established physical treatments? Results from an Australasian clinical panel review. Aust N Z J Psychiatry. 1999; 33(6): 874-881.

18. Gillman PK. CNS toxicity involving methylene blue: the exemplar for understanding and predicting drug interactions that precipitate serotonin toxicity. J Psychopharmacol. 2011; 25(3): 429-436.

19. Wimbiscus M, Kostenko O, Malone D. MAO inhibitors: risks, benefits, and lore. Cleve Clin J Med. 2010; 77(12): 859-882.

20. Gillman PK. A review of serotonin toxicity data: implications for the mechanisms of antidepressant drug action. Biol Psychiatry. 2006; 59(11): 1046-1051.

21. Gillman PK. Monoamine oxidase inhibitors, opioid analgesics and serotonin toxicity. Br J Anaesth. 2005; 95(4): 434-441.

22. Gillman PK. Triptans, serotonin agonists, and serotonin syndrome (serotonin toxicity): a review. Headache. 2009; 50(2): 264-272.

23. Isbister GK, Buckley NA, Whyte IM. Serotonin toxicity: a practical approach to diagnosis and treatment. Med J Aust. 2007; 187(6): 361-365.

24. Shioda K, Nisijima K, Yoshino T, Kato S. Mirtazapine abolishes hyperthermia in an animal model of serotonin syndrome. Neurosci Lett. 2010; 482(3): 216-219.

25. Gillman PK. A systematic review of the serotonergic effects of mirtazapine: implications for its dual action status. Hum Psychopharmacol. 2006; 21(2): 117-125.

26. Otte W, Birkenhager TK, van den Broek WW. Fatal interaction between tranylcypromine and imipramine. Eur Psychiatry. 2003 18(5): 264-265.

27. Gillman PK. Serotonin syndrome: history and risk. Fundam Clin Pharmacol. 1998; 12(5): 482-491.

28. Gillman PK. Tricyclic antidepressant pharmacology and therapeutic drug interactions updated. Br J Pharmacol. 2007; 151(6): 737-748.

29. Sullivan EA, Shulman KI. Diet and monoamine oxidase inhibitors: a re-examination. Can J Psychiatry. 1984; 29(8): 707-711.

30. Gillman PK. Monoamine oxidase inhibitors: A review concerning dietary tyramine and drug interactions. PsychoTropical Commentaries. 2016; 16(6): 1-97; http://www.psychotropical.com/ images/Publications-pdfs/MAOI_diet_drug_interactions_2016.pdf. Accessed June 2017, 2016.

31. Bullock D, Irvine O. A chromatographic study of cheddar cheese ripening. Journal of Dairy Science. 1956; 39(9): 1229-1235.

32. Blackwell B, Marley E. Interactions of yeast extracts and their constituents with monoamine oxidase inhibitors. Br J Pharmacol. 1965; 26(1): 142-161.

33. Tulman DB, Stawicki SP, Papadimos TJ, Murphy CV, Bergese SD. Advances in management of acute hypertension: a concise review. Discov Med. 2012; 13(72): 375-383.

34. Marik PE, Rivera R. Hypertensive emergencies: an update. Curr Opin Crit Care. 2011; 17(6): 569-580.

35. Flanigan JS, Vitberg D. Hypertensive emergency and severe hypertension: what to treat, who to treat, and how to treat. Med Clin North Am. 2006; 90(3): 439-451.

36. Griesemer EC, Barsky J, Dragstedt CA, Wells JA, Zeller EA. Potentiating effect of iproniazid on the pharmacological action of sympathomimetic amines. Proc Soc Exp Biol Med. 1953; 84(3): 699-701.

37. Corne S, Graham J. The effect of inhibition of amine oxidase in vivo on administered adrenaline, noradrenaline, tyramine and serotonin. J Physiol. 1957; 135(2): 339-349. 